University of Wollongong

Research Online

Australian Institute for Innovative Materials -

Papers

Australian Institute for Innovative Materials

$1-1-2015$

Flexible free-standing graphene paper with interconnected porous structure for energy storage

Kewei Shu

University of Wollongong, ks323@uowmail.edu.au

Caiyun Wang

University of Wollongong, caiyun@uow.edu.au

Sha Li

University of Wollongong, sl739@uowmail.edu.au

Chen Zhao

University of Wollongong, cz995@uowmail.edu.au

Yang Yang

University of Wollongong, yy214@uow.edu.au

See next page for additional authors

Follow this and additional works at: https://ro.uow.edu.au/aiimpapers

Part of the Engineering Commons, and the Physical Sciences and Mathematics Commons

Research Online is the open access institutional repository for the University of Wollongong. For further information contact the UOW Library: research-pubs@uow.edu.au 


\title{
Flexible free-standing graphene paper with interconnected porous structure for energy storage
}

\author{
Abstract \\ A novel porous graphene paper is prepared via freeze drying a wet graphene oxide gel, followed by \\ thermal and chemical reduction. The macroscopic structure of the formed graphene paper can be tuned \\ by the water content in the gel precursor. With $92 \%$ water content, an interconnected macroporous \\ network can be formed. This porous graphene (PG) paper exhibits excellent electrochemical properties. It \\ can deliver a high discharge capacity of $420 \mathrm{~mA} \mathrm{~h} \mathrm{~g}^{-1}$ at a current density of $2000 \mathrm{~mA} \mathrm{~g}^{-1}$ when used as \\ binder-free lithium ion battery anode. PG paper exhibits a specific capacitance of $137 \mathrm{~F} \mathrm{~g}^{-1}$ at $1 \mathrm{~A} \mathrm{~g}^{-1}$ in a \\ flexible all-solid-state supercapacitor with PVA $/ \mathrm{H}_{2} \mathrm{SO}_{4}$ electrolyte. It can maintain $94 \%$ of its capacitance \\ under bending. This electrochemical performance and mechanical flexibility makes it an excellent \\ material for flexible energy storage devices.

\section{Keywords} \\ paper, graphene, storage, standing, energy, free, flexible, structure, porous, interconnected \\ Disciplines \\ Engineering | Physical Sciences and Mathematics

\section{Publication Details} \\ Shu, K., Wang, C., Li, S., Zhao, C., Yang, Y., Liu, H. \& Wallace, G. (2015). Flexible free-standing graphene \\ paper with interconnected porous structure for energy storage. Journal of Materials Chemistry A, 3 (8), \\ 4428-4434.

\section{Authors} \\ Kewei Shu, Caiyun Wang, Sha Li, Chen Zhao, Yang Yang, Hua-Kun Liu, and Gordon G. Wallace
}




\title{
Journal Name
}

\section{ARTICLE}

Cite this: DOI: $10.1039 / \times 0 \times x 00000 x$

\section{Flexible Free-standing Graphene Paper with Interconnected Porous Structure for Energy Storage}

\author{
Kewei Shu, ${ }^{\mathrm{a}}$ Caiyun Wang, ${ }^{* \mathrm{a}}$ Sha $\mathrm{Li},{ }^{\mathrm{a}, \mathrm{b}}$ Chen Zhao, ${ }^{\mathrm{a}}$ Yang Yang, ${ }^{\mathrm{a}}$ Huakun Liu, ${ }^{\mathrm{b}}$ Gordon Wallace ${ }^{{ }^{\mathrm{a}}}$
}

Received 00th January 2012, Accepted 00th January 2012

DOI: $10.1039 / \times 0 x \times 00000 x$

www.rsc.org/
A novel porous graphene paper is prepared via freeze drying a wet graphene oxide gel, followed by thermal and chemical reduction. The macroscopic structure of the formed graphene paper can be tuned by the water content in the gel precursor. With $92 \%$ water content, an interconnected macroporous network can be formed. This porous graphene (PG) paper exhibits excellent electrochemical properties. It can deliver a high discharge capacity of $420 \mathrm{mAh} \mathrm{g}^{-1}$ at a current density of $2000 \mathrm{~mA} \mathrm{~g}^{-1}$ when used as binder-free lithium ion battery anode. PG paper exhibits a specific capacitance of $137 \mathrm{~F} \mathrm{~g}^{-1}$ at $1 \mathrm{~A} \mathrm{~g}^{-1}$ in a flexible all-solidstate supercapacitor with $\mathrm{PVA} / \mathrm{H}_{2} \mathrm{SO}_{4}$ electrolyte. It can maintain $94 \%$ of its capacitance under bending. This electrochemical performance and mechanical flexibility makes it an excellent material for flexible energy storage devices.

\section{Introduction}

With the increasing interests in portable electronics, lightweight, flexible and high performance energy storage devices are extensively studied. ${ }^{1,2}$ For the flexible energy storage units, the most important challenge is to fabricate electrodes that can sustain good electrochemical properties upon bending. Carbon based free-standing thin films or papers are promising flexible binder-free electrodes due to its flexibility and excellent electrochemical properties. ${ }^{3-5}$ Among the carbon materials family, graphene offers outstanding electrochemical properties for energy storage application, ${ }^{6,7}$ due to its intriguing properties such as excellent conductivity, exceptionally large specific surface area and extraordinary electronic transport properties. ${ }^{8-10}$

Flexible binder-free graphene or graphene composite electrodes can be fabricated due to the large aspect ratio of the individual graphene sheets. These electrodes have found applications in flexible batteries/supercapacitors. ${ }^{11-14}$ The restacking of graphene sheets due to strong $\pi-\pi$ interactions during the fabrication process deteriorates performance as the accessible surface area is decreased limiting the electrochemical properties. There exist two main strategies to inhibit the restacking of graphene sheets: the incorporation of spacers separating the graphene sheets and the creation of three-dimensional porous networks. Spacers used include surfactants, polymers, nanoparticles and even water. ${ }^{15-18}$ The approaches used to construct threedimensional porous graphene assembly involve the technique of hydrothermal, ${ }^{19}$ template-assisted CVD, organic sol-gel ${ }^{20,21}$ and freeze drying. ${ }^{22-24}$

Freeze drying is a simple, versatile, low-cost and environmentally friendly fabrication technique for porous structures. ${ }^{25}$ It has been widely used in the research of tissue engineering and other biological applications. ${ }^{26}$ Recently, freeze casting has been used to create porous graphene material. A highly-ordered three-dimensional architecture with microchannels oriented along the freezing direction could be fabricated using a polymer stabilized graphene aqueous dispersion. ${ }^{22}$ An ultralight graphene based aerogels with monolithic three-dimensional framework can be prepared by quickly freezing the graphene dispersion 
followed by freeze drying process. ${ }^{24}$ The graphene monoliths can be made superelastic via tuning the reduction level of the graphene precursor and controlling the freeze drying conditions. ${ }^{23}$ However, such produced macroscopic graphene aerogel generally possesses large pore size (over $150 \mu \mathrm{m})$, ultra-low density and mechanical fragility. A mechanical pressing procedure was applied to form paperlike electrode, subsequently part of the porous structure was lost. $^{27}$

In this work, we report a mechanically strong flexible graphene paper with an interconnected porous structure. This paper can be fabricated directly by a simple freeze drying strategy. It demonstrates superior electrochemical performance when used as an electrode in lithium batteries or in all-solid-state supercapacitors. The intrinsic mechanical flexibility of such graphene paper allows it to be used as binder-free electrode directly without the need for mechanical pressing.

\section{Experimental}

\subsection{Material synthesis and device fabrication}

Graphite oxide was synthesized from natural graphite flakes using the modified Hummers method. ${ }^{6,} 28$ The obtained graphite oxide was subjected to ultrasonication using a Brandson Digital Sonifier (S450D) for $30 \mathrm{~min}$ (30\% amplitude, $2 \mathrm{~s}$ on, $1 \mathrm{~s}$ off) to obtain graphene oxide (GO). Graphene oxide wet "gel" was formed by vacuum filtration of a $24 \mathrm{~mL} 1 \mathrm{mg} \mathrm{mL}^{-1} \mathrm{GO}$ dispersion $(0.22 \mu \mathrm{m}$ polycarbonate membrane), followed by a quickly frozen procedure with liquid nitrogen. The frozen graphene gel was then subject to a freeze-drying process in a freeze drier (Christ Alpha 1-2 LD plus). The as-prepared GO paper was thermally reduced at $220^{\circ} \mathrm{C}$ in air for $2 \mathrm{~h}$, followed by further reduction with $5 \%$ ascorbic acid solution for $6 \mathrm{~h}$ at $60{ }^{\circ} \mathrm{C}$. Two types of wet "gel" precursor, containing $92 \%$ and $87 \%$ water, were used in this work. The resultant graphene paper was named G-92, G-87, respectively. The water content was measured by thermal gravity analysis. For comparison, graphene paper from air dried wet "gel” was also prepared for comparison. It was named as G-air paper.

For lithium battery test, the graphene paper sample was assembled into LR 2032 type coin cell coupled with lithium metal using $1 \mathrm{M} \quad \mathrm{LiPF}_{6}$ in $1: 1 \quad(\mathrm{v} / \mathrm{v})$ ethylene carbonate/dimethyl carbonate as electrolyte. To fabricate flexible all-solid-state supercapacitor, the graphene paper was pasted onto gold-coated PET substrate using silver paste. A gel electrolyte, PVA/ $\mathrm{H}_{2} \mathrm{SO}_{4}$ (1:1, weight ratio) was prepared following the procedure described in our previous report, ${ }^{29}$ and dropped onto the graphene electrode and dried at room temperature for $12 \mathrm{~h}$. Two such electrodes were held together using fresh polymer electrode as glue (Figure 1).

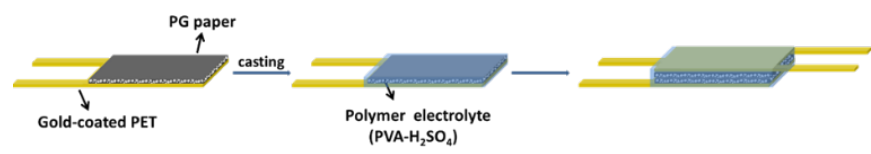

Figure 1 Schematic procedure to fabricate flexible all solid-state supercapacitors.

\subsection{Characterization}

The morphology was investigated using atomic force microscope (AFM, Asylum MFP) and field-emission scanning electron microscope (FESEM, JEOL JSM7500FA). XRD measurements were performed on an Australia GBC Scientific X-ray diffract meter $\left(\mathrm{Cu} \mathrm{K}_{\alpha}\right.$ radiation, $\lambda=1.5418 \mathrm{~A}^{\circ}$ ) at a scan rate of $2^{\circ} \mathrm{min}^{-1}$. The thermal properties were characterized by TGA (Q500, TA instruments), and the measurements were tested under nitrogen with a ramp rate of $5^{\circ} \mathrm{C} \mathrm{min}^{-1}$. Conductivity measurements were carried out on a Jandel RM3 Conductivity Meter using a four-point probe method.

Galvanostatic charge/discharge tests for lithium battery were performed using a LAND CT2001A battery test system (Wuhan Jinnuo Electronics Co. Ltd. China) over a potential range of $0.005-3.0 \mathrm{~V}$ (vs. $\mathrm{Li} / \mathrm{Li}^{+}$). Cyclic voltammetry for lithium battery was tested using a Solartron SI 1287 and scanned between 0.0 to $3.0 \mathrm{~V}$ (vs. $\mathrm{Li}^{2} \mathrm{Li}^{+}$) at a rate of $0.1 \mathrm{mV} \mathrm{s}^{-1}$. For all-solid-state supercapacitor, the electrochemical tests were conducted using a battery test system (galvanostatic charge/discharge test, Neware Electronic Co. China) and EA163 potentiostat (CV test, eDAQ Pty. Ltd.). Electrochemical impedance spectroscopy (EIS) measurements were performed using a Gamry EIS 3000 system, and the frequency range spanned from 100 $\mathrm{kHz}$ to $0.01 \mathrm{~Hz}$ with amplitude of $10 \mathrm{mV}$ at open circuit potential.

\section{Results and discussion}

The prepared graphene oxide was analysed by X-Ray photoelectron spectroscopy (XPS). A typical C1s spectrum of graphene oxide shows four components corresponding to 
different functional groups, indicative of the considerable degree of oxidation (Figure 2a). The non-oxygenated ring $\mathrm{C}$ (C-C), $\mathrm{C}$ in $\mathrm{C}-\mathrm{O}$ bonds, carbonyl $\mathrm{C}(\mathrm{C}=\mathrm{O})$ and carboxylate $\mathrm{C}(\mathrm{O}-\mathrm{C}=\mathrm{O})$ appears at $284.8 \mathrm{eV}, 286.8 \mathrm{eV}, 287.8 \mathrm{eV}$ and $288.6 \mathrm{eV}$, respectively. Atomic force microscopy shows that the evaporated graphene oxide dispersion cast on silicon wafer consists of isolated graphene sheets. ${ }^{30}$ Although the theoretical thickness of single layered graphene sheet is $\sim 0.34 \mathrm{~nm}$, the graphene oxide sheets are expected to be thicker due to the presence of functional groups and absorbed water molecules. ${ }^{31}$ Our graphene nanosheet is several hundred nanometres in lateral dimension and 1.2 $\mathrm{nm}$ in thickness, suggesting the successful exfoliation of graphite oxide (Figure 2b).

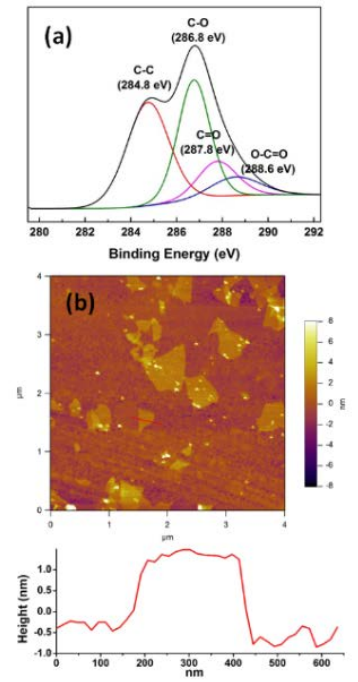

Figure 2 XPS spectrum of graphene oxide (a) and AFM image and height profile of graphene oxide (b).

The morphology of the fracture edge of the G-92, G-87 and G-air graphene paper was presented in Figure 3. G-92 paper exhibits a cross-linked porous network with pore size around several micrometres. We label this graphene paper as PG to denote the porous structure. G-87 paper displayed a loosely compacted layered structure with micro-scale interspaces (Figure 3b). For air dried graphene paper (G-air), a more compact layered structure with large interspaces was observed (Figure 3c). PG paper displayed a high thickness due to the high porosity, approximately $150 \mu \mathrm{m}$. It is not unexpected that the formation of layered structure results in the thickness shrinkage. The thickness of G-87 paper and G- air paper was $\sim 15 \mu \mathrm{m}$ and $\sim 10 \mu \mathrm{m}$, respectively, only $1 / 10$ and 1/15 of PG paper's thickness. The conductivity for PG, G-87 and G-air paper is $8 \mathrm{~S} \mathrm{~m}^{-1}, 43 \mathrm{~S} \mathrm{~m}^{-1}$ and $62 \mathrm{~S} \mathrm{~m}^{-1}$, respectively. The conductivity of PG paper is relatively low due to the high inter-sheet contact resistance within the porous structure. ${ }^{20}$ However, we should point out that this conductivity is higher than that of the previously reported $3 \mathrm{D}$ porous graphene assemblies $\left(0.5 \mathrm{~S} \mathrm{~m}^{-1}\right)$ obtained using a hydrothermal method. ${ }^{19}$ Interestingly, such highly porous graphene paper (PG, G-92) is still flexible and robust (Figure 3d). The PG paper can maintain its porous structure even after being constructed into a coin cell coupled with Lithium foil and subjected to 100 charge/discharge cycles (Figure 3a inset).

The water content in the gel-like graphene precursor is a vital factor in forming the porous structure. The arrangement of graphene sheets in solution/gel is attributed to the balance between electrostatic repulsion (originating from the functional group on the edge of graphene sheets) and interaction forces arising from hydrogen bonding and $\pi-\pi$ interaction. ${ }^{32,}{ }^{33}$ When the binding interaction is reinforced by filtration and becomes the main driving force, the graphene sheets in the gel tend to arrange a layered structure. Once the water was removed by air drying, the intersheet interaction could be further reinforced due to the partial flattening of the graphene sheets, forming a compact layered structure. ${ }^{18}$ Within a wet gel containing $87 \% \mathrm{H}_{2} \mathrm{O}$, still water remains tightly adsorbed onto graphene, forming hydrated graphene sheets. Such hydrated graphene sheets are then assembled as a less compact layered structure after freeze drying due to the trapped water. This type of structure has been previously reported for a graphene gel obtained from reduced graphene oxide after freeze drying. ${ }^{34}$ When the water content was increased (92\%), the excess unconfined free water allows the colloidal electrostatic repulsion to hinder the parallel alignment of graphene sheets, forming a graphene porous network with free water trapped inside. When frozen by liquid nitrogen, the extremely low temperature leads to the rapid formation of ice nuclei and the growth of small ice crystals. ${ }^{35}$ The sublimation of such ice crystals creates a continuous porous network, like the structure of freeze dried graphene hydrogel with a high water content (97.4 \%). ${ }^{19}$ 


\section{Journal Name}

\section{ARTICLE}
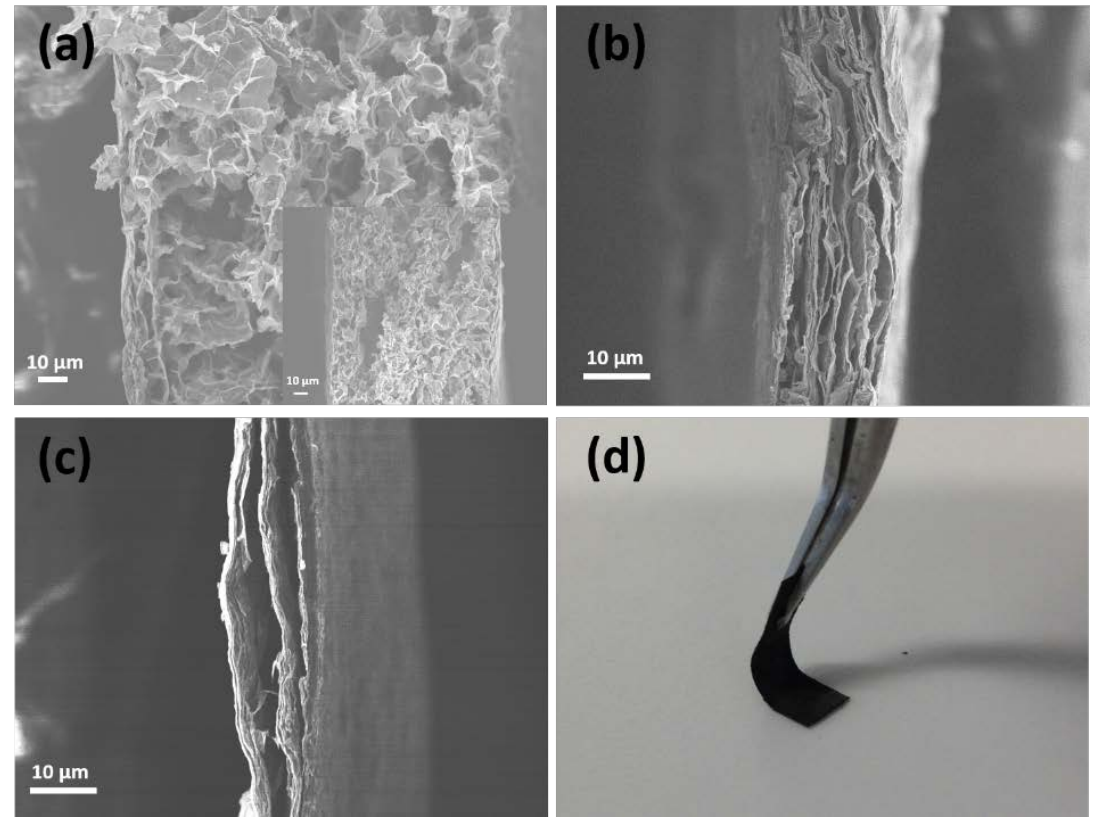

Figure 3 SEM image of the cross section of PG (a), G-87 (b) and G-air graphene paper. Photograph demonstrating the flexibility of PG paper (d). (Figure3a inset: SEM image of cycle PG paper.)

Figure 4a shows the XRD spectra obtained for porous graphene oxide (PGO, before reduction) and PG paper. PGO paper shows a strong and sharp peak at $10.0^{\circ}$, corresponding to a $d$-spacing of $0.88 \mathrm{~nm}$. PG paper displays a broad and weak peak at around $24^{\circ}$. The $d$-spacing for the PG paper decreased to $0.37 \mathrm{~nm}$ due to the removal of oxygencontaining functional groups between interlayer of graphene sheets. The peak in PG paper is broader and weaker, indicating a less ordered state caused by the porous structure. $^{36}$ Raman spectra of PGO and PG paper were presented in Figure 4b. They all displayed a typical $\mathrm{G}$ band (1583 $\mathrm{cm}^{-1}$ ) and $\mathrm{D}$ band $\left(1334 \mathrm{~cm}^{-1}\right)$, corresponding to the first order scattering of the $E_{2 g}$ mode ( $G$ band) and disordered structures (D band), respectively. ${ }^{37}$ The $D / G$ intensity ratio is 1.20 for PGO, and 1.40 for PG. Such D/G ratio change can be attributed to the decrease in the average size of the $\mathrm{sp}^{2}$ domains upon reduction. The $\mathrm{D} / \mathrm{G}$ intensity ratio increased from 1.40 to 1.67 after the PG paper was subjected to 100 charge/discharge cycles (Figure 4c). The increased D/G ratio indicates higher degree of disorder, which may be ascribed to more defects created in the graphene nanosheets due to the repeated lithium intercalation-deintercalation process. ${ }^{38}$

(a)
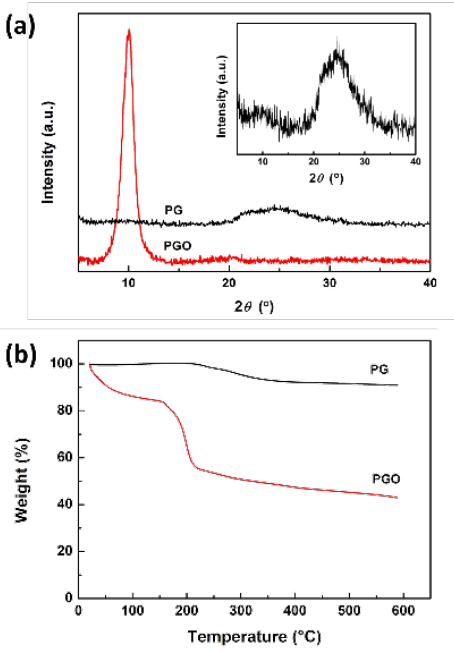

(c)

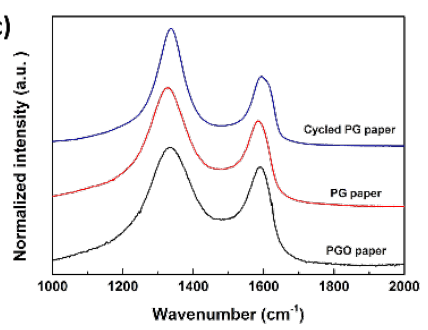

Figure 4 XRD patterns (a) and TGA curves (b) of PGO and PG Japers. (c) Raman spectra of PG, PGO paper and cycled PG paper. Figure 4a inset: expanded peak view for PG paper $\left(5-40^{\circ}\right)$ ). 
PGO paper or PG paper shows a typical TGA curve for GO and reduced GO materials (Figure 4c). The hydrophilic PGO paper demonstrated a $\sim 10 \%$ weight loss below $100{ }^{\circ} \mathrm{C}$ due to the evaporation of absorbed water, and a $\sim 30 \%$ loss between $100-200{ }^{\circ} \mathrm{C}$ (Figure 4c). The later weight loss was caused by pyrolysis of oxygen-containing groups. ${ }^{39}$ PG paper displayed negligible weight loss in this temperature range, which indicates the successful reduction of the PGO paper. The weight loss of PG and PGO paper in the temperature range of $200{ }^{\circ} \mathrm{C}$ to $500{ }^{\circ} \mathrm{C}$ is similar, $~ 10 \%$, and is attributed to the decomposition of the residual oxygen-containing groups. ${ }^{40}$ The Raman Spectra, TGA curves of G-87 and G-air paper were not shown here due to their similarity.

Since the graphene electrode structure described here is to be used in liquid media, the methylene blue (MB) solution adsorption was used to determine surface area, as has been described previously. ${ }^{41,42} \mathrm{MB}$ is commonly used to evaluate the specific surface area of nanostructured carbon materials. A surface area of 148 and $18 \mathrm{~m}^{2} \mathrm{~g}^{-1}$ was obtained for PG and G-87 paper, respectively. The graphene paper exhibited a negligible surface area. Such big difference in the surface area can be ascribed to their structures as revealed by SEM images.
The performance of PG paper as binder-free electrode for lithium-ion battery was studied by galvanostatic charge/discharge in the potential range of 0.005 to $3.0 \mathrm{~V}$. PG paper displayed a very high first discharge capacity of 1200 $\mathrm{mAh} \mathrm{g}^{-1}$ and a reversible capacity of $1056 \mathrm{mAh} \mathrm{g}^{-1}$ at the second cycle (Figure 5a). G-87 paper could deliver a similar first discharge capacity of $1260 \mathrm{mAh} \mathrm{g}^{-1}$, but much lower reversible discharge capacity of $841 \mathrm{mAh} \mathrm{g}^{-1}$. Not surprisingly, G-air paper presented the lowest discharge capacity, a first charge capacity of $894 \mathrm{mAh} \mathrm{g}^{-1}$ and a reversible discharge capacity of $287 \mathrm{mAh} \mathrm{g}^{-1}$ (Figure 5b). The interconnected three dimensional porous structures in the PG graphene paper could provide more lithium insertion active sites, thus leading to much higher reversible capacity. The higher reversible capacity of G-87 paper than that of G-air paper could be attributed to its loosely packed layered structure. The G-air paper possesses a much higher restacking level of graphene sheets, which limits the active site and the accessibility of ions and electrolyte.

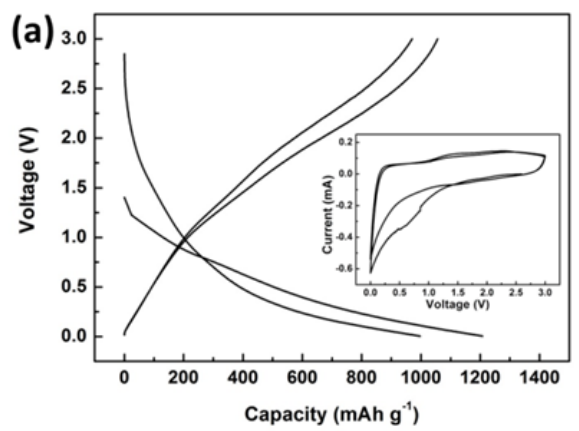

(b)
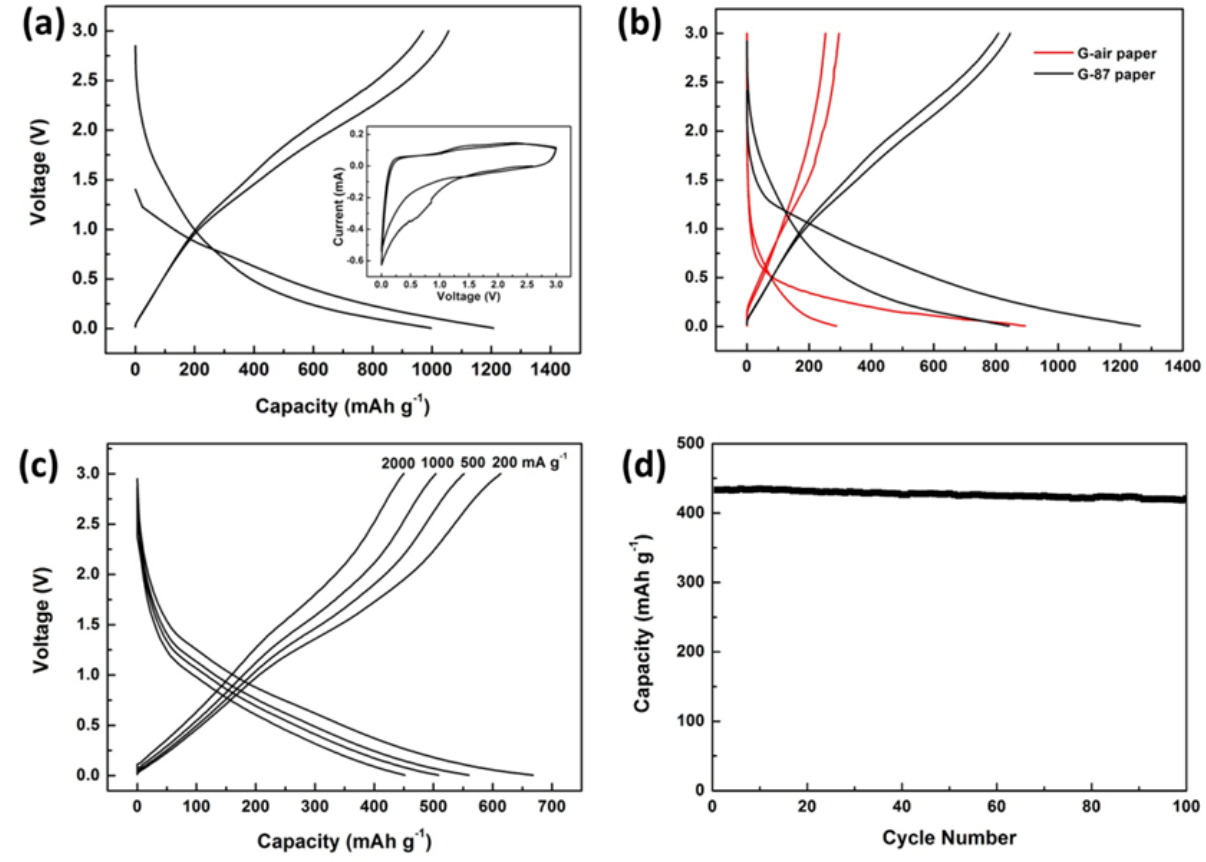

Figure 5 First and second charge discharge curves of PG paper (a), G-air papers and G-87 paper (b). (c) Charge discharge curves of PG paper at different current densities. (d) Capacity versus cycle number at $2000 \mathrm{~mA} \mathrm{~g}^{-1}$. (Figure 5a inset: cyclic voltammograms of PG paper at a scan rate of $0.1 \mathrm{mV} \mathrm{s}^{-1}$ ).

The lithium intercalation occurs in the potential range below $0.5 \mathrm{~V}$ for PG paper (inset in Figure 6a), which became weaker after the first circle due to the lithium intercalation reaction is not fully reversible. The cathodic peak around $0.75 \mathrm{~V}$, which only appears in the first circle, indicates the formation of solid electrolyte interface (SEI). The cathodic peak at about $1.5 \mathrm{~V}$ attributes to lithium interactions with the residual functional groups on the 
surface or on the edge sites of graphene sheets. This irreversible capacity loss could be attributed to the formation of SEI layer and the reaction of lithium ion with residual oxygen-containing functional group. ${ }^{7}$ These results are in good agreement with the charge discharge curves.

The PG paper also delivered good rate capability. At a current density of $200,500,1000$ and $2000 \mathrm{~mA} \mathrm{~g}^{-1}$, the corresponding reversible capacity could reach 683, 600, 518 and $428 \mathrm{mAh} \mathrm{g}^{-1}$, respectively (Figure 5c). This high rate discharge/charge capability is due to the enhanced accessibility of ions and electrolyte benefited from the unique porous structure. Our PG paper can deliver a capacity of $420 \mathrm{mAh} \mathrm{g}^{-1}$ at $2000 \mathrm{~mA} \mathrm{~g}^{-1}$, much higher than that reported $300 \mathrm{mAh} \mathrm{g}^{-1}$ at $186 \mathrm{~mA} \mathrm{~g}^{-1}$ for previous filtrated graphene paper electrodes. ${ }^{43}$ This performance is also much better than that $\left(141 \mathrm{mAh} \mathrm{g}^{-1}\right.$ at $\left.1500 \mathrm{~mA} \mathrm{~g}^{-1}\right)$ obtained using graphene paper prepared by mechanically pressing a freeze dried graphene aerogel. ${ }^{44}$ This paper also demonstrated a good cycling stability (Figure 5d). After 100 cycles, our PG paper electrode still maintains a capacity of $420 \mathrm{mAh} \mathrm{g}^{-1}$ at a current density of $2000 \mathrm{~mA} \mathrm{~g}^{-1}, 97 \%$ of the initial capacity. This result was higher than that of the pressed graphene cryogel paper we previously reported. ${ }^{27}$

The electrochemical properties of this PG paper were also investigated after being assembled into an all-solid-state supercapacitor. G-87 and G-air paper based supercapacitor were also evaluated for comparison (Figure 6a). The CV curve of PG based supercapacitor shows a near rectangular shape at a scan rate of $10 \mathrm{mV} \mathrm{s}^{-1}$, with a high single electrode specific capacitance of $\sim 148 \mathrm{~F} \mathrm{~g}^{-1}$. A distorted rectangular CV response was presented by G-87 paper, indicating its poorer capacitive performance. G-87 paper delivered a low specific capacitance of $\sim 36 \mathrm{~F} \mathrm{~g}^{-1}$. Not surprising $\mathrm{G}$-air paper delivers a negligible capacitance at 10 $\mathrm{mV} \mathrm{s}^{-1}$. The rectangular CV loop of PG paper became slightly distorted when the scan rate reached $20 \mathrm{mV} \mathrm{s}^{-1}$ and $50 \mathrm{mV} \mathrm{s}^{-1}$, and the capacitance was $118 \mathrm{~F} \mathrm{~g}^{-1}$ and $74 \mathrm{~F} \mathrm{~g}^{-1}$ respectively.
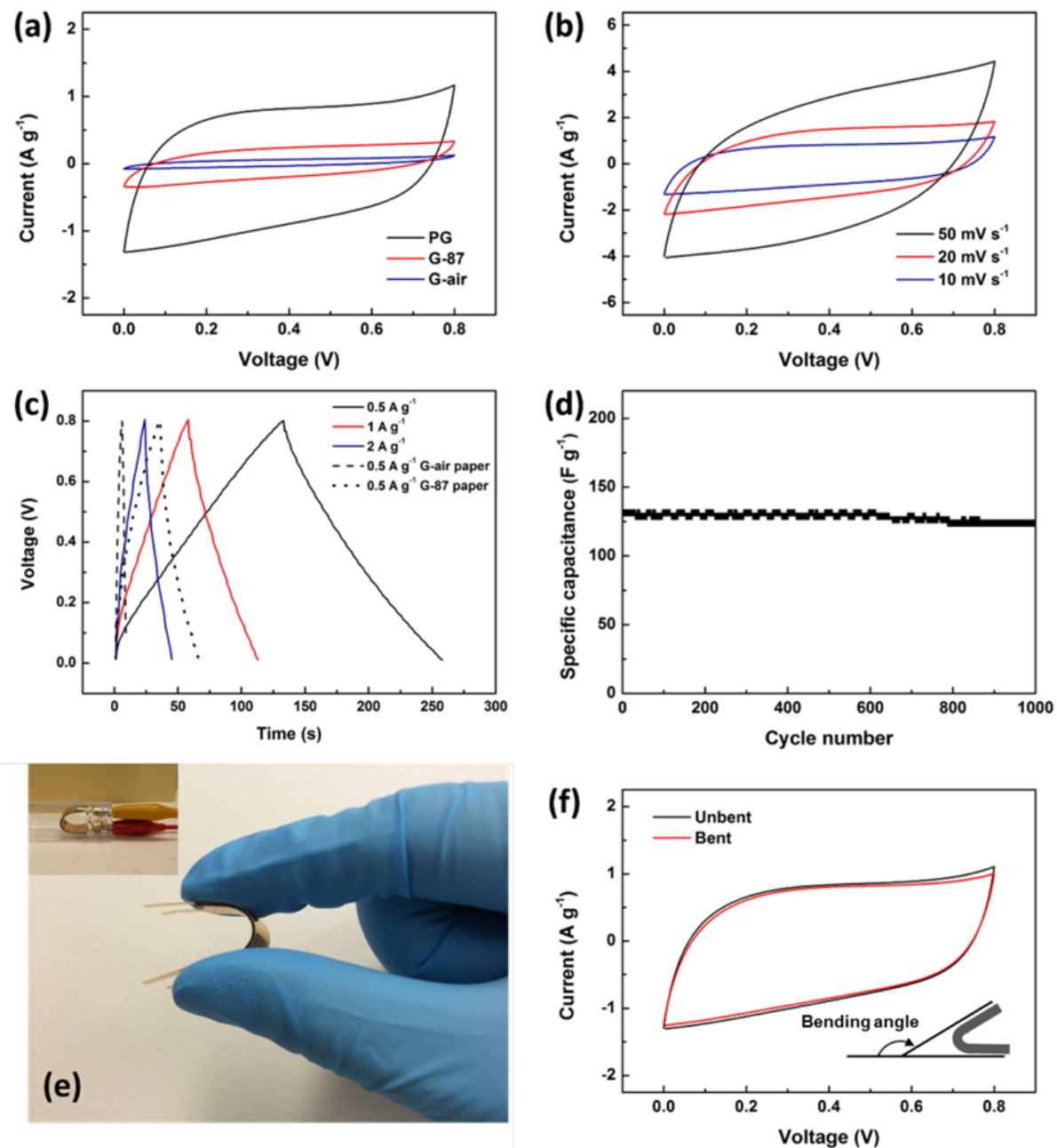


\section{Journal Name}

\section{ARTICLE}

Figure 6 (a) Cyclic voltammograms of PG paper, G-87 paper and G-air paper at a scan rate of $10 \mathrm{mV} \mathrm{s}$. $^{-1}$ (b) Cyclic voltammograms for PG paper based flexible solid-state supercapacitor at different scan rate. (c) Charge discharge curves of PG paper (solid line), G-87 paper (dot line) and G-air paper (dash line) based flexible supercapacitor. (d) Cycle stability of PG paper supercapacitor at a current density of 1 A g ${ }^{-1}$. (e) Digital image of a flexible and bendable PG paper based supercapacitor. (f) Cyclic voltammograms of PG paper based supercapacitor (bending and relaxation state) at a scan rate of $10 \mathrm{mV} \mathrm{s}^{-1}$.

The discharge curve obtained using PG paper is nearly straight, indicating a good electrical double layer performance (Figure 6c). The specific capacitance for a single electrode $\boldsymbol{C}_{\boldsymbol{s}}$ is calculated from charge discharge curves using equation:

$$
C_{s}=\frac{2 I \Delta t}{m \Delta V}
$$

Where $\boldsymbol{I}$ is the discharge current, $\Delta t$ is the time for a full discharge, $\boldsymbol{m}$ is the mass of a single electrode, and $\boldsymbol{\Delta} \boldsymbol{V}$ represents the potential window. The specific capacitance of PG flexible supercapacitor was $156 \mathrm{~F} \mathrm{~g}^{-1}$ at $0.5 \mathrm{~A} \mathrm{~g}^{-1}$. It decreased to $105 \mathrm{~F} \mathrm{~g}^{-1}$ at a higher current density of $2 \mathrm{~A} \mathrm{~g}^{-1}$. PG paper based solid-state supercapacitor shows a comparable performance to the previously reported carbon nanotube based solid-state devices. ${ }^{45-47}$ In sharp contrast, G87 paper and G-air paper only delivered a specific capacitance of $38 \mathrm{~F} \mathrm{~g}^{-1}$ and $5 \mathrm{~F} \mathrm{~g}^{-1}$ at $0.5 \mathrm{~A} \mathrm{~g}^{-1}$ (Figure 6c, dot line and dash line). The capacitance became negligible when the current density increased to $2 \mathrm{~A} \mathrm{~g}^{-1}$ (not shown here). The formation of the layered structure in graphene paper decreased the surface area, resulting in the poor performance. ${ }^{48}$ For PG paper, its porous structure offers high surface area facilitating the easy ionic transportation and enhanced accessibility of electrolyte, thus lead to the high capacitance.

To further characterize the cycle stability of the solidstate device, galvanostatic charge/discharge tests were carried out at a current density of $1 \mathrm{~A} \mathrm{~g}^{-1}$ (Figure 6d). Only $\sim 6 \%$ decay in specific capacitance was observed after 1000 charge/discharge cycles. The Coulombic efficiency was in the range of $98-100 \%$. This flexible supercapacitor also exhibit good mechanical robustness. It could be repeatedly bent over 100 times at over $120^{\circ}$ bending angle without significant variations in specific capacitance. It displayed nearly the same capacitive behaviour in the bent and unbent state (94\% capacitance retention upon bending) (Figure 6f), indicating that electrochemical property change is negligible when is subjected to bending.

\section{Conclusions}

A novel graphene paper with a continuous porous structure was prepared using a graphene wet gel as precursor and a simple lyophilisation process. The water content in the precursor graphene oxide gel was used to prevent the restacking of graphene sheets. The structure formed could be tuned from a loosely compact layered structure to a continuous connected porous network with the water content in the gel precursor. The porous graphene (PG) paper displayed an enhanced electrochemical performance in lithium batteries and all-solid supercapacitors. The highly interconnected 3D structure allows fast charge transfer and rapid ion diffusion, thus enhances its electrochemical performance. This PG paper is mechanically robust and flexible; make it a promising electrode used in wearable or rolling-up devices. Also, its open porous structure allows the fabrication of porous graphene-based composites via incorporation with other functional materials into the void space.

\section{Acknowledgements}

The authors thank the Australian Research Council (ARC) for financial support under the ARC Centre of Excellence for Electromaterials Science. The authors also acknowledge the ANFF Materials Node for their provision of research facilities and the use of facilities within UOW Electron Microscopy Centre. Kewei Shu and Chen Zhao acknowledge the support of the CSC scholarship from the Ministry of Education of P. R. China.

\section{Notes and references}


${ }^{\text {a }}$ Intelligent Polymer Research Institute, ARC Centre of Excellence for Electromaterials Science, University of Wollongong, Wollongong, NSW 2522 Australia.

${ }^{\mathrm{b}}$ Institute for Superconducting and Electronic Materials, University of Wollongong, Wollongong, NSW 2522 Australia.

*Tel: +61 2 42981426. Fax: +61 24221 3124. E-mail: caiyun@uow.edu.au (C.W.).

Tel: +61 2 42213127. Fax: +61 2 42213124. E-mail: gwallace@uow.edu.au (G.G.W.).

1. H. Nishide and K. Oyaizu, Science, 2008, 319, 737-738.

2. V. L. Pushparaj, M. M. Shaijumon, A. Kumar, S. Murugesan, L. Ci, R. Vajtai, R. J. Linhardt, O. Nalamasu and P. M. Ajayan, Proc. Natl. Acad. Sci. U. S. A., 2007, 104, 13574-13577.

3. S. H. Ng, J. Wang, Z. P. Guo, G. X. Wang and H. K. Liu, Electrochim. Acta, 2005, 51, 23-28.

4. G. Xu, C. Zheng, Q. Zhang, J. Huang, M. Zhao, J. Nie, X. Wang and F. Wei, Nano Res., 2011, 4, 870-881.

5. A. Izadi-Najafabadi, T. Yamada, D. N. Futaba, M. Yudasaka, H. Takagi, H. Hatori, S. Iijima and K. Hata, ACS Nano, 2011, 5, 811-819.

6. M. D. Stoller, S. J. Park, Y. W. Zhu, J. H. An and R. S. Ruoff, Nano Letters, 2008, 8, 3498-3502.

7. E. Yoo, J. Kim, E. Hosono, H. Zhou, T. Kudo and I. Honma, Nano Letters, 2008, 8, 2277-2282.

8. C. Lee, X. Wei, J. W. Kysar and J. Hone, Science, 2008, 321, 385388.

9. S. V. Morozov, K. S. Novoselov, M. I. Katsnelson, F. Schedin, D. C. Elias, J. A. Jaszczak and A. K. Geim, Physical Review Letters, 2008, 100.

10. A. Peigney, C. Laurent, E. Flahaut, R. R. Bacsa and A. Rousset, Carbon, 2001, 39, 507-514.

11. A. Sumboja, C. Y. Foo, X. Wang and P. S. Lee, Adv. Mater., 2013, 25, 2809-2815.

12. H.-P. Cong, X.-C. Ren, P. Wang and S.-H. Yu, Energy \& Environmental Science, 2013, 6, 1185-1191.

13. N. Jung, S. Kwon, D. Lee, D.-M. Yoon, Y. M. Park, A. Benayad, J.Y. Choi and J. S. Park, Adv. Mater., 2013, 25, 6854-6858.

14. C. Wang, D. Li, C. O. Too and G. G. Wallace, Chemistry of Materials, 2009, 21, 2604-2606.

15. S. Park, N. Mohanty, J. W. Suk, A. Nagaraja, J. H. An, R. D. Piner, W. W. Cai, D. R. Dreyer, V. Berry and R. S. Ruoff, Adv. Mater., 2010, 22, 1736-1740.

16. G. K. Wang, X. Sun, F. Y. Lu, H. T. Sun, M. P. Yu, W. L. Jiang, C. S. Liu and J. Lian, Small, 2012, 8, 452-459.
17. Q. Wu, Y. X. Xu, Z. Y. Yao, A. R. Liu and G. Q. Shi, ACS Nano, 2010, 4, 1963-1970.

18. X. Yang, J. Zhu, L. Qiu and D. Li, Adv. Mater., 2011, 23, 2833-2838.

19. Y. Xu, K. Sheng, C. Li and G. Shi, ACS Nano, 2010, 4, 4324-4330.

20. Z. Chen, W. Ren, L. Gao, B. Liu, S. Pei and H.-M. Cheng, Nat Mater, 2011, 10, 424-428.

21. M. A. Worsley, P. J. Pauzauskie, T. Y. Olson, J. Biener, J. H. Satcher and T. F. Baumann, Journal of the American Chemical Society, 2010, 132, 14067-14069.

22. J. L. Vickery, A. J. Patil and S. Mann, Adv. Mater., 2009, 21, 21802184.

23. L. Qiu, J. Z. Liu, S. L. Y. Chang, Y. Wu and D. Li, Nat Commun, 2012, 3, 1241.

24. H. Sun, Z. Xu and C. Gao, Adv. Mater., 2013, 25, 2554-2560.

25. H. Zhang, I. Hussain, M. Brust, M. F. Butler, S. P. Rannard and A. I. Cooper, Nat Mater, 2005, 4, 787-793.

26. S. V. Madihally and H. W. T. Matthew, Biomaterials, 1999, 20, 11331142.

27. K. Shu, C. Wang, M. Wang, C. Zhao and G. G. Wallace, Journal of Materials Chemistry A, 2014, 2, 1325-1331.

28. W. S. Hummers and R. E. Offeman, Journal of the American Chemical Society, 1958, 80, 1339-1339.

29. C. Zhao, C. Wang, Z. Yue, K. Shu and G. G. Wallace, ACS Applied Materials \& Interfaces, 2013, 5, 9008-9014.

30. S. Stankovich, R. D. Piner, X. Chen, N. Wu, S. T. Nguyen and R. S. Ruoff, Journal of Materials Chemistry, 2006, 16, 155-158.

31. S. Stankovich, D. A. Dikin, R. D. Piner, K. A. Kohlhaas, A. Kleinhammes, Y. Jia, Y. Wu, S. T. Nguyen and R. S. Ruoff, Carbon, 2007, 45, 1558-1565.

32. H. Bai, C. Li, X. Wang and G. Shi, Chemical Communications, 2010, 46, 2376-2378.

33. H. Bai, C. Li, X. Wang and G. Shi, The Journal of Physical Chemistry C, 2011, 115, 5545-5551.

34. X. Yang, L. Qiu, C. Cheng, Y. Wu, Z.-F. Ma and D. Li, Angewandte Chemie International Edition, 2011, 50, 7325-7328.

35. L. Qian and H. Zhang, Journal of Chemical Technology \& Biotechnology, 2011, 86, 172-184.

36. A. Abouimrane, O. C. Compton, K. Amine and S. T. Nguyen, The Journal of Physical Chemistry C, 2010, 114, 12800-12804.

37. F. Tuinstra and J. L. Koenig, The Journal of Chemical Physics, 1970, 53, 1126-1130.

38. R. Kostecki and F. McLarnon, Journal of Power Sources, 2003, 119, 550-554.

39. O. C. Compton, D. A. Dikin, K. W. Putz, L. C. Brinson and S. T. Nguyen, Adv. Mater., 2010, 22, 892-896.

40. H. Chen, M. B. Mueller, K. J. Gilmore, G. G. Wallace and D. Li, Adv. Mater., 2008, 20, 3557-3561.

41. J. J. Kipling and R. B. Wilson, Journal of Applied Chemistry, 1960, 10, 109-113. 
42. J. Zhu, C. Cheng, X. Yang, Y. Wang, L. Qiu and D. Li, Chemistry-a European Journal, 2013, 19, 3082-3089.

43. H. Gwon, H.-S. Kim, K. U. Lee, D.-H. Seo, Y. C. Park, Y.-S. Lee, B. T. Ahn and K. Kang, Energy \& Environmental Science, 2011, 4, 1277-1283.

44. F. Liu, S. Song, D. Xue and H. Zhang, Adv. Mater., 2012, 24, 10891094.

45. Y. J. Kang, S.-J. Chun, S.-S. Lee, B.-Y. Kim, J. H. Kim, H. Chung, S.Y. Lee and W. Kim, ACS Nano, 2012, 6, 6400-6406.
46. Y. Xu, Z. Lin, X. Huang, Y. Liu, Y. Huang and X. Duan, ACS Nano, 2013, 7, 4042-4049.

47. Z. Weng, Y. Su, D.-W. Wang, F. Li, J. Du and H.-M. Cheng, Advanced Energy Materials, 2011, 1, 917-922.

48. Y. Yoon, K. Lee, C. Baik, H. Yoo, M. Min, Y. Park, S. M. Lee and H. Lee, Adv. Mater., 2013, 25, 4437-4444. 


\section{Graphical Abstract}

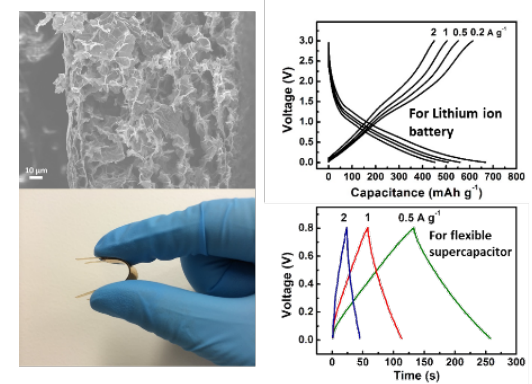

Flexible porous graphene paper was obtained via facile freeze drying method. It exhibits an excellent electrode performance in both the lithium battery and solid-state supercapacitor. 